\title{
Silicone-induced granuloma of breast implant capsule (SIGBIC): similarities and differences with anaplastic large cell lymphoma (ALCL) and their differential diagnosis
}

\author{
This article was published in the following Dove Press journal: \\ Breast Cancer - Targets and Therapy \\ 10 March 2017 \\ Number of times this article has been viewed
}

\author{
Eduardo de Faria Castro \\ Fleury' \\ Milena Morais Rêgo' \\ Luciana Costa Ramalho' \\ Veronica Jorge Ayres' \\ Rodrigo Oliveira Seleti \\ Carlos Alberto Pecci \\ Ferreira $^{2}$ \\ Decio Roveda $\mathrm{Jr}^{2}$ \\ 'Radiology Department, IBCC - \\ Instituto Brasileiro de Controle \\ do Câncer, ${ }^{2}$ Irmandade Santa Casa \\ de Misericórdia de São Paulo, \\ São Paulo, Brazil
}

\begin{abstract}
Primary breast lymphoma is a rare disease and accounts for $0.5 \%$ of cases of breast cancer. Most primary breast lymphomas develop from B cells, and the involvement of T cells is rare. Anaplastic large cell lymphoma (ALCL) is a recently discovered T-cell lymphoma associated with breast implants. Only a few cases have been reported to date. It is believed that the incidence of ALCL is increasing because of the increasing number of breast implants. The clinical presentation is variable and can manifest as a palpable mass in the breast or armpit, breast pain, or capsular contracture. Because of the rarity of the disease and the lack of knowledge to date, clinical diagnosis is often delayed, with consequent delays in treatment. The cause and pathogenesis have not been fully elucidated, and there are no evidence-based guidelines for diagnosis, treatment, or follow-up of this disease. We present a review of cases of patients with silicone breast implants, including ALCL, a rare type of breast cancer that is still under study, and silicone-induced granuloma of breast implant capsule and its differential diagnosis, and discuss if a silicone-induced granuloma of breast implant capsule could be the precursor of the disease.
\end{abstract}

Keywords: lymphoma, granuloma, breast cancer, implant

\section{Introduction}

Breast cancer is the most common cancer among women and is considered the leading cause of cancer mortality among women in Brazil. More than 95\% of cases of breast cancer are carcinomas. Other malignant tumors may occasionally develop in breast tissues, including sarcomas, secondary metastases, and lymphomas. ${ }^{1}$

\section{Primary breast lymphoma}

Primary breast lymphomas (PBLs) are rare neoplasms, representing approximately $0.5 \%$ of the cases of breast cancers and $2 \%$ of the cases of extranodal lymphomas. ${ }^{2}$ PBLs originate from periductal and perilobular lymphoid tissues of the breast and may be related to lymphoid tissues associated with mucous membranes. ${ }^{3}$ Most PBLs are derived from B cells, and tumors with T-cell phenotypes are rare (less than $6 \%$ cases). ${ }^{4}$ The average age at onset of PBL is 57 years. ${ }^{5}$

The clinical and radiological manifestations of PBL are indistinguishable from those of other breast tumors. Therefore, immunohistochemistry is fundamental for the diagnosis of these tumors. ${ }^{4}$
Correspondence: Eduardo de Faria Castro Fleury

Rua Maestro Chiaffarelli, 409, Jardim Paulista - São Paulo 01432-030, Brazil Tel +55 I| 98|48 I I88

Email edufleury@hotmail.com 
These tumors are usually single, painless, and welldefined and have an elastic consistency.

The diagnostic criteria originally defined for PBL continue to serve as the standard definition of the disease, ${ }^{6}$ which include the following:

- An initial site of disease presentation in the breasts;

- The absence of a previous history of lymphoma;

- The absence of disseminated disease at diagnosis;

- An association between the lymphoma and breast tissue on histopathological examination;

- An association between the axillary lymph nodes involvement with breast lymphoma.

\section{Anaplastic large cell lymphoma (ALCL)}

Anaplastic large cell lymphoma (ALCL) is a rare subtype of non-Hodgkin lymphoma of T cells; it represents approximately $3 \%$ of cases of non-Hodgkin lymphoma. ${ }^{7}$

Most of the described cases (81\%) correspond to ALCL and involve the presence of $\mathrm{CD} 30^{+}$and the absence of the ALK gene. $^{8}$

$\mathrm{ALCL} \mathrm{CD} 30^{+}$occurs as a result of the activation and abnormal proliferation of T lymphocytes; it may present in cutaneous or systemic forms. The expression of the $A L K$ gene allows the classification of ALCL into two subtypes, which help determine prognosis. The morphological and cytological characteristics of ALCL associated with breast implants are similar to those of systemic ALK-negative ALCL; however, the latter has a poor prognosis, whereas breast implant-associated ALK-negative ALCL is typically an indolent disease with a much better prognosis. ${ }^{9}$

The interest in ALCL has been motivated by reports of cases of PBLs associated with saline and silicone implants. These cases usually involve surgical findings, and the diagnosis before surgery is unknown..$^{10-12}$

The first case of ALCL associated with breast implants was described in 1997 by Keech and Creech. ${ }^{13}$ In 2011, the United States Food and Drug Administration issued a statement confirming 60 cases of ALCL associated with prosthesis. ${ }^{14}$ Since then, the number of cases of ALCL has increased, presumably due to the growing number of breast implants and the greater knowledge of the disease pathology.

The reported incidence of ALCL is one case per 500,000 women with breast implants. The age at onset varies between 34 and 59 years, with an average of 46 years. The disease develops within approximately 3-7 years, with a mean of 5 years after mammoplasty. ${ }^{11}$

ALCL affects the fibrous capsule around the implant, rarely appears as a solid mass and does not involve the breast parenchyma. ${ }^{9}, 15$ The initial presentation in most patients includes seroma without spontaneous resolution, capsular contracture, or peri-implant masses ${ }^{8}$ (Figure 1).

The mechanism involved in the development of lymphoma is uncertain, ${ }^{11}$ and its pathogenesis is currently under
A

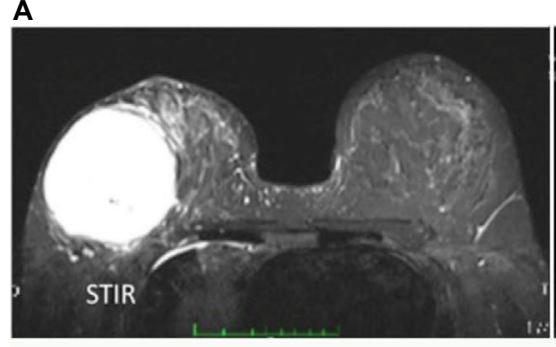

D

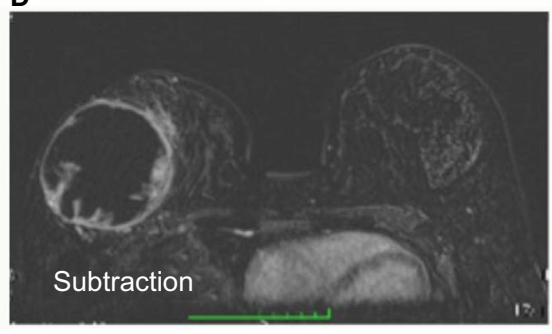

B

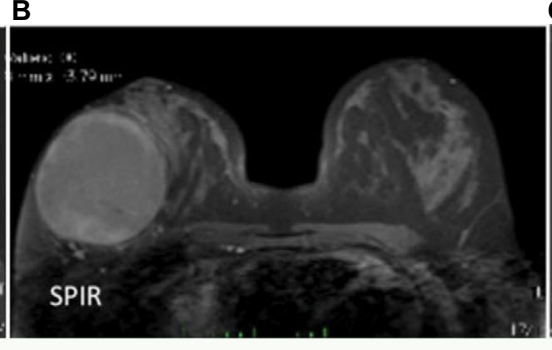

E

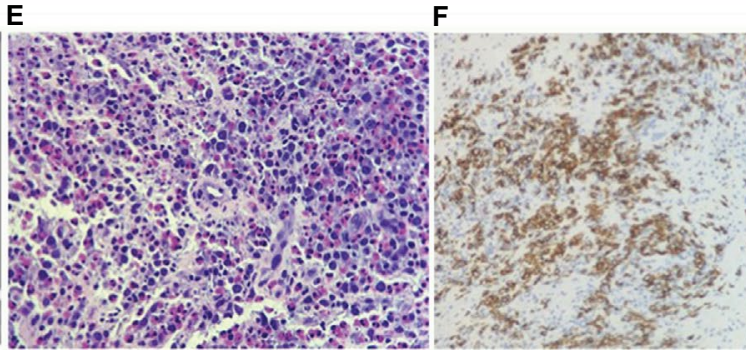

Figure I A 57-year-old patient with asymmetric enlargement of the right breast and clinical signs of capsular contracture.

Notes: MRI images in (A) STIR, (B) SPIR, (C) after the injection of contrast agent, and (D) with subtraction show the heterogeneous tissue in the space between the fibrous capsule and the breast implant associated with fluid fill. These findings are compatible with ALCL. Specimen of core needle biopsy of the lesion shows a proliferation of monoclonal T lymphocytes (E). The immunohistochemistry is positive for CD30+ $(\mathbf{F})$. The diagnosis was confirmed as ALCL. Magnification $\times 500$.

Abbreviations: MRI, magnetic resonance imaging; STIR, short-TI inversion recovery; SPIR, spectral presaturation with inversion recovery; ALCL, anaplastic large cell lymphoma. 
investigation. However, the mechanism may involve an immune response induced by the silicone or polyurethane material in the implant, which may cause an immune overreaction and induce monoclonal neoplasia with activated $\mathrm{T}$ lymphocytes. Other postulated mechanisms involve an indirect reaction mediated by cytokines and toxic damage induced by silicone. ${ }^{16}$

Microscopic leakage of silicone from the interior of the prosthesis into the intracapsular area has been described even in cases in which implants are not ruptured. In the case of saline or silicone implants, the capsules may be responsible for chronic local inflammation with T-cell activation and clonal expansion. ${ }^{11}$

\section{Silicone-induced granuloma of breast implant capsule (SIGBIC)}

The SIGBIC is probably a resultant of an autoimmune/ inflammatory syndrome induced by silicone (ASIA syndrome). The association between autoimmunity and silicon exposure, similar to that causing the ALCL, may result in the following scenario:

- Silicone leaks from the interior of a normal implant into the intracapsular space;

- Silicon-containing particles are captured by macrophages, resulting in entrapment within lysosomes;

- These macrophages are activated, resulting in the production of cytokines, for example, interleukin-1b, reactive oxygen species, and reactive nitrogen species;

- Apoptosis of macrophages result in the release of siliconcontaining particles that can be taken up once again by other macrophages.

Exposure to silicon-containing particles also leads to a massive production of interleukin-17, resulting in an influx of neutrophils that are activated and produce reactive oxygen species and release of myeloid granular enzymes such as myeloperoxidase. Additionally, if there is a capsular disruption, silicon-containing particles are transported to the regional lymph nodes, resulting in a pronounced adjuvant effect. Silica particles induce a type- 2 inflammatory response characterized by increase in $\operatorname{IgE}$ and $\operatorname{IgG1}$ and chronic activation of $\mathrm{T}$ cells, possibly because negative regulators of $\mathrm{T}$ cells are dysfunctional in combination with dysfunction of regulatory $\mathrm{T}$ cells. It is known that silicones may undergo oxidization to silica and that silicon-containing gel induces an adjuvant effect. ${ }^{17}$

Searching the bibliographic databases online on the web, no reference was found to silicone-induced granuloma in intact breast implants. As seen above, the pathophysiology of ALCL is very similar to that of SIGBIC, where the only difference would be monoclonal neoplasia induced by activation of $\mathrm{T}$ lymphocytes. Because they are very rare entities, new studies need to be performed to determine whether ALCL is an evolution of SIGBIC. We also believe that SIGBIC should be underdiagnosed in clinical practice due to its benign course.

\section{Diagnosis \\ Clinical examination}

Clinically, ALCL may present as seroma without spontaneous resolution, capsular contracture, or peri-implant masses, ${ }^{8}$ while SIGBIC may present as a mass. The conditions usually have an indolent course and excellent prognosis, with a good response to excision of the fibrous capsule and removal of the implant. In contrast, cases that involve the presence of masses can be more aggressive and can have poor prognoses. ${ }^{15}$

\section{Image diagnosis}

The image features of ALCL and SIGBIC will be similar, although ALCL could present as fluid fill within the intracapsular space, while SIGBIC is most often present as an intracapsular mass. It is important to emphasize that the implant should be intact, without signals of visible ruptures by imaging methods.

Mammography is usually the first clinical examination conducted (Figure 2). However, in patients with capsular contracture, their performance may be difficult due to the breast stiffness. Patients must complete a consent form for the examination owing to the risk of rupture by compression of the device.

Ultrasound is the second most common examination and is usually interpreted in conjunction with the mammogram. Ultrasound may be used to guide punctures or biopsies; one

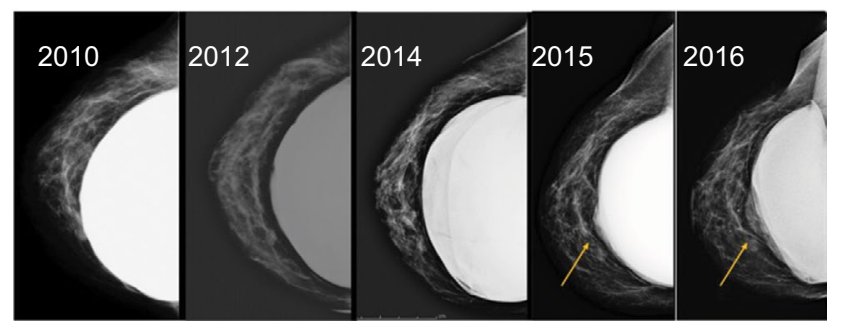

Figure 2 A 53-year-old patient at the breast screening program.

Notes: Sequence of mammography shows a mass developing at the fibrous capsule of the implant in the year of 2015 and subcapsular mass that increase in size in 2016, when compared to 2015 mammogram (arrows). It was given BI-RADS category 4 , but she and her physician opted to follow up the lesion. One year later the mass grows up and was given a BI-RADS category 4 again.

Abbreviation: BI-RADS, breast imaging reporting and data system. 
of its advantages is its low cost. ALCL findings are often not very specific. Approximately two-thirds of patients present fluid collection around the implant, which is observed in the images, and one-third are characterized by the presence of masses (Figure 3).

Magnetic resonance imaging (MRI) has the best sensitivity for the assessment of suspected cases of lymphoma and evaluation of the integrity of the implant. For these reasons, MRI is widely used in clinical practice (Figure 4).

\section{Cytological/anatomopathological diagnosis}

Diagnosis can be made by cytology of the seroma or biopsy of the capsule. ${ }^{5}$ In cases of recurrent seroma that develop approximately 6 months or more after mammoplasty, cytological examination of the aspirate is recommended because the lymphoma cells are found in seroma around the implant, in the fibrous capsule or within a peri-implant mass. ${ }^{8,18}$ Typically, there is no invasion, other than the fibrous capsule, into the breast parenchyma ${ }^{18}$ (Figure 5).

The differential diagnosis between ALCL and SIGBIC is made essentially by the presence of anaplastic monoclonal $\mathrm{T}$ cell at optic microscopy, enhanced by $\mathrm{CD} 30^{+}$and $\mathrm{CD} 3$ immunostain.

\section{Differential diagnosis}

No masses should be present in the virtual space between the fibrous capsule and the breast implant. If present, these masses limit the differential diagnosis of ALCL and SIGBIC (Figure 6).

The main differential diagnosis includes the presence of seroma, capsular contracture, late hematoma, and late inflammatory/infectious processes.

Seroma is one of the complications associated with breast implants. It consists of an exudate between the fibrous capsule
A

A
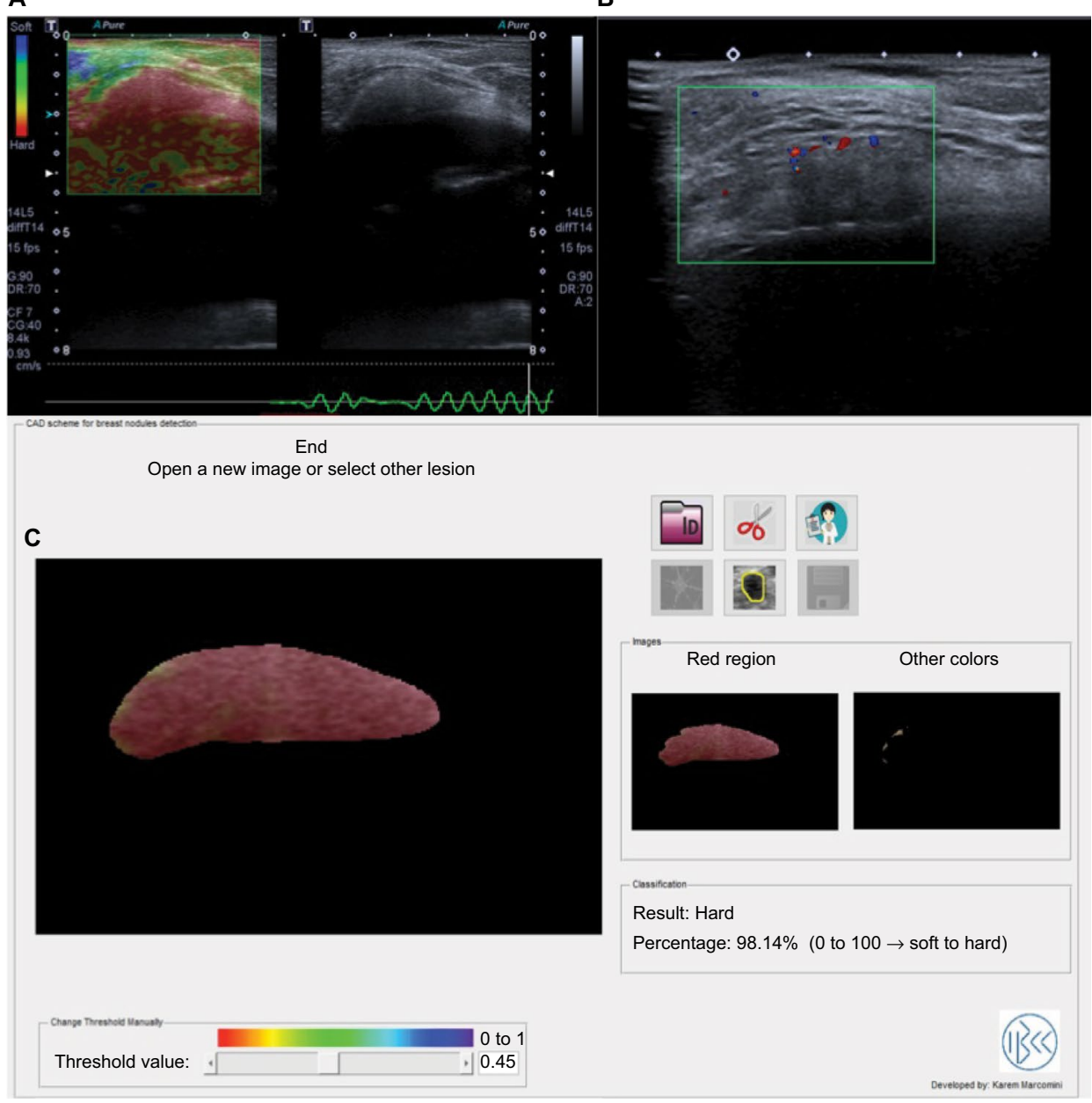

Figure 3 The same 53-year-old patient noted in the earlier figure underwent ultrasound scan that shows (A) a hard mass at the elastography, (B) with high vascularity at the color Doppler scan, and (C) when processing a CAD software of the lesion, the result shows a mass composed essentially of hard tissue, $98.14 \%$ of hard tissue. Abbreviation: CAD, computer-assisted diagnosis. 


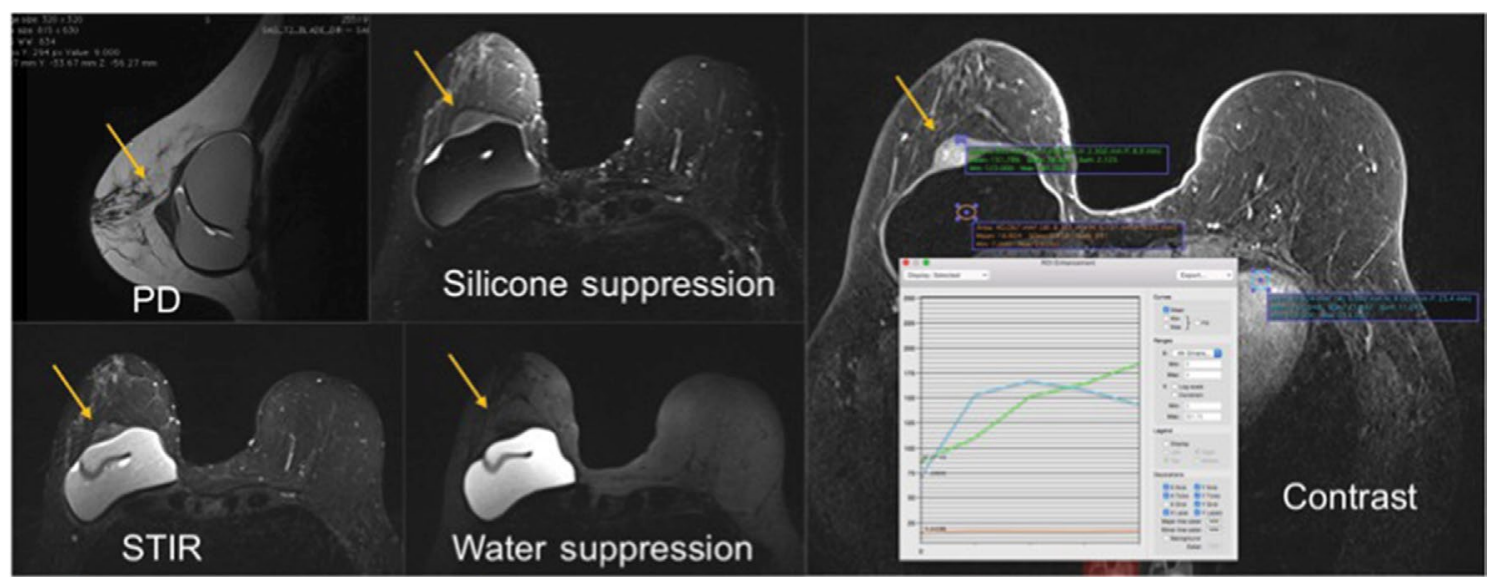

Figure $4 \mathrm{MRI}$ of the same 53 -year-old patient noted in the earlier figures.

Notes: A fibrous mass at the same regions of the earlier figures was observed. The characteristics of the signals show a fibrous lesion, with low signal at all sequences and enhancement after the contrast injection. Arrows indicate subcapsular mass with contrast enhancement. There is no signal of implant rupture.

Abbreviations: PD, proton density; STIR, short TI inversion recovery; MRI, MRI, magnetic resonance imaging.

A

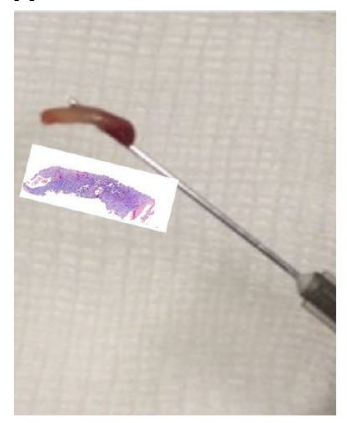

D

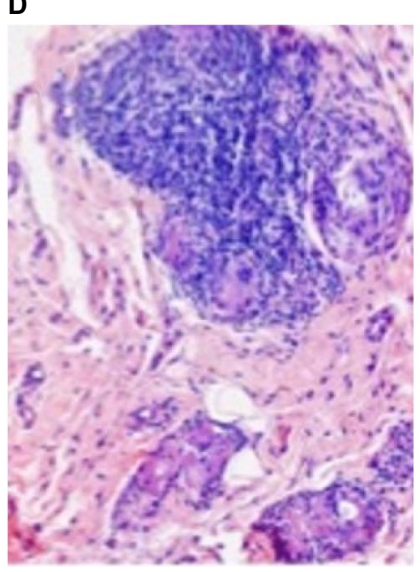

B

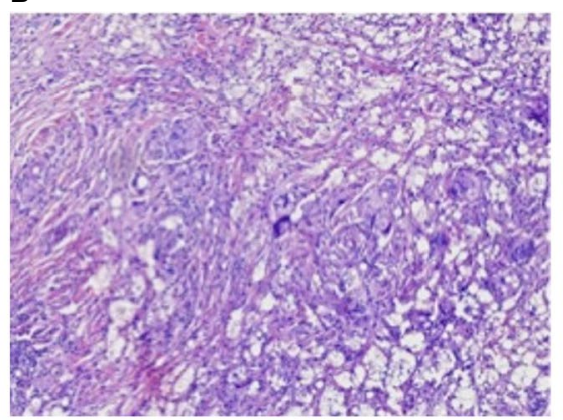

C

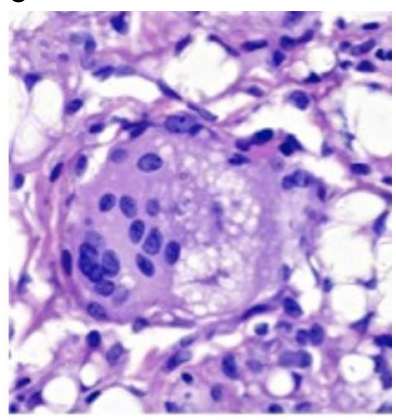

E

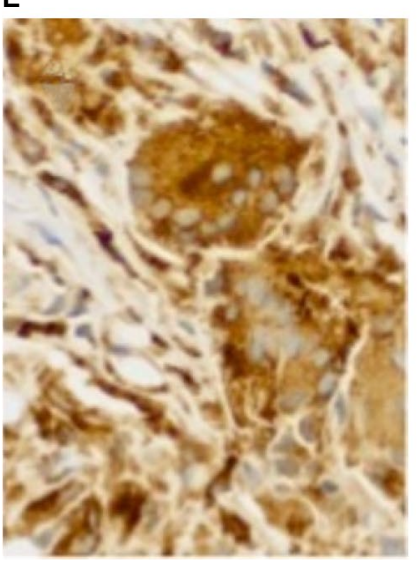

Figure 5 Specimen of core needle biopsy of the lesion shows a rigid lesion.

Notes: The microscopic analysis shows (A) epithelioid granulomatous process with giant cells induced by silicone (B-E). CD68 immunohistochemistry positivity, denoting histiocytic nature of cells. The diagnosis was confirmed as SIGBIC. Magnification for (B) $\times 40 ;($ C $) \times 500 ;($ D) $\times 100$; (E) $\times 500$.

Abbreviation: SIGBIC, silicone-induced granuloma of breast implant capsule.

and the implant that is typically reabsorbed spontaneously. The complication is considered late when its clinical manifestation occurs more than 12 months after the procedure. In general, most of the seromas described in the literature are associated with Biocell textured implants, which favor the development of double capsules. ${ }^{19}$ Double capsules usually occur when there is detachment of the fibrous capsule from the surface of the implant, forming a local seroma/hematoma. After resorption, a new, second, capsule is formed.

Capsular contracture results from the proliferation of fibrous scar tissues in the adjacent fibrous capsule; these tissues compress and deform the implant. This complication 


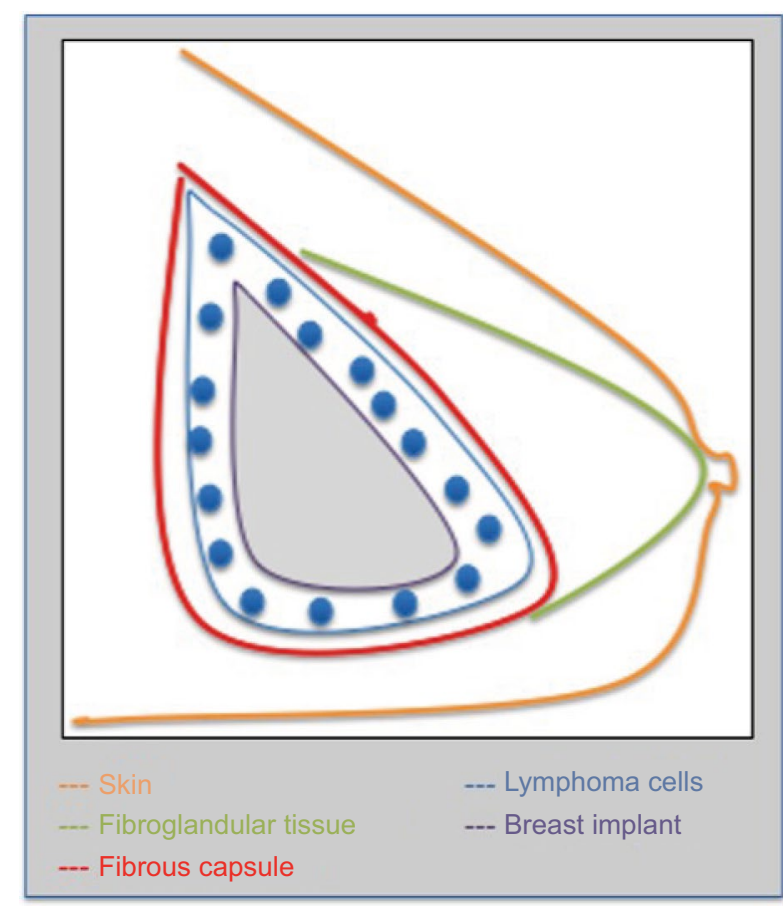

Figure 6 Schematic representation of the location of ALCL and SIGBIC. Abbreviations: ALCL, anaplastic large cell lymphoma; SIGBIC, silicone-induced granuloma of breast implant capsule.

may be due to infection, hematoma, or seroma ${ }^{20}$ (Figure 7). Its clinical scoring follows the classification of Baker and includes the following four grades:

- Grade I: soft breast, with normal visual appearance;

- Grade II: slight stiffening of the breast, with normal visual appearance;

- Grade III: hardening of the breast, with abnormal visual appearance (deformity); and

- Grade IV: hardened breast, with pain and significant visual deformity.

Late hematoma originates from medium-sized arteries located in the implant capsule. Chronic bleeding of these arteries is caused by microfractures in the fibrous capsule. Because of the rigidity of the prosthesis, the retraction of the damaged vessel is limited, which favors new bleeding ${ }^{21}$ (Figure 8).

Late infection can occur after cosmetic surgeries such as breast augmentation, in which $2.9 \%$ of patients present infection in the surgical bed; among those affected, $1.7 \%$ cases are acute, and $0.8 \%$ cases are late. These rates are higher in patients undergoing mastectomy and reconstruction because of the complexity of the procedures and range between $1 \%$ and $53 \%$. The onset of late infection may vary from a few months to several years and is different between saline implants (onset within 8 weeks, with an average of 4 weeks) and silicone implants (onset within 24 weeks, with an average of 8 weeks). Late infections are caused by the colonization of prostheses secondary to blood bacteremia. The microorganisms involved are gram-positive and gram-negative bacteria. Coagulase-negative staphylococci and Propionibacterium acnes are the most common strains. The diagnosis is made by liquid culture of the material obtained by fine-needle aspiration, and empirical treatment with vancomycin should be conducted with antibiotics until the results of antibiogram susceptibility testing become available, based on the high number of infections due to $\beta$-lactam resistant pathogens, among which are methicillin-resistant Staphylococcus aureus and coagulase-negative staphylococci ${ }^{22}$ (Figure 9).

The main differential diagnoses are not correlated with the presence of masses with anomalous enhancement on MRI. Therefore, the injection of a paramagnetic agent (gadolinium) is essential in MRI examinations of breast implants to determine if the diagnosis of ALCL or SIGBIC should be discarded because of the consequences of late diagnosis. Without the use of contrast media, it is not possible to evaluate the presence of solid masses in the hematoma.

We suppose that SIGBIC is subdiagnosed at the clinical practice due to some factors: lack of information about the implant status at the surgery for the pathologist, and most often the material of capsulotomy is not sent for histological examination. We believe it could be a precursor of the ALCL because both have the same physiopathogeny.

\section{Treatment}

The treatment proposed for ALCL and SIGBIC is almost the same: removal of the prosthesis and fibrous capsule. Chemotherapy or adjuvant radiotherapy is not indicated in cases confined to the capsule for ALCL. ${ }^{23}$ Despite the poor prognosis of ALK-negative ALCL, the primary cases with silicone implants appear to have an indolent course, with good response to treatment and better disease-free survival. ${ }^{8}$ The reported rate of cure is higher than $90 \%$. Cases with clinical presentation of solid masses are often more aggressive; in such instances, secondary therapy, such as chemotherapy and radiation, is recommended. ${ }^{23,24}$

\section{Conclusion}

Although ALCL and SIGBIC are rare, knowledge about these diseases is essential in patients subjected to diagnostic MRI for the assessment of breast implants because treatment is simple and involves the removal of the prosthesis and the capsule around the prosthesis. Therefore, a contrast agent should be used for the evaluation of breast implants on MRI to ensure that a diagnosis is made before the surgery for 


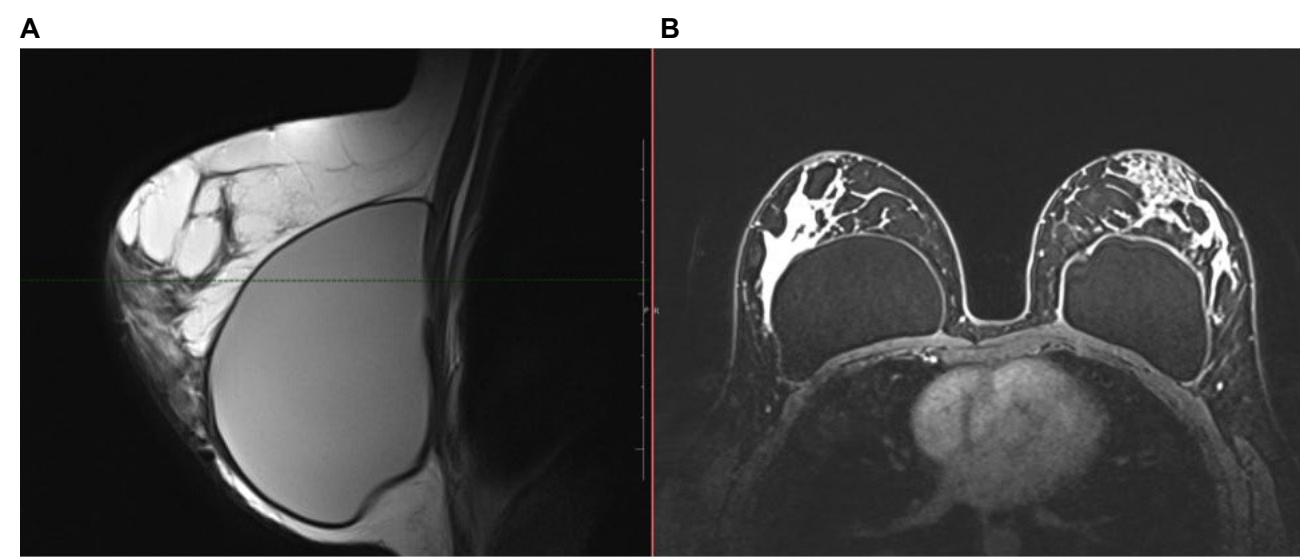

Figure 7 A 43-year-old patient with thickening and discomfort in the left breast.

Notes: (A) Sagittal PD images of the left breast and (B) axial images after injection of the contrast agent show the increase in the anteroposterior diameter of the left breast implant, with thickening of the fibrous capsule and enhanced contrast compared with the right side.

Abbreviation: PD, proton density.
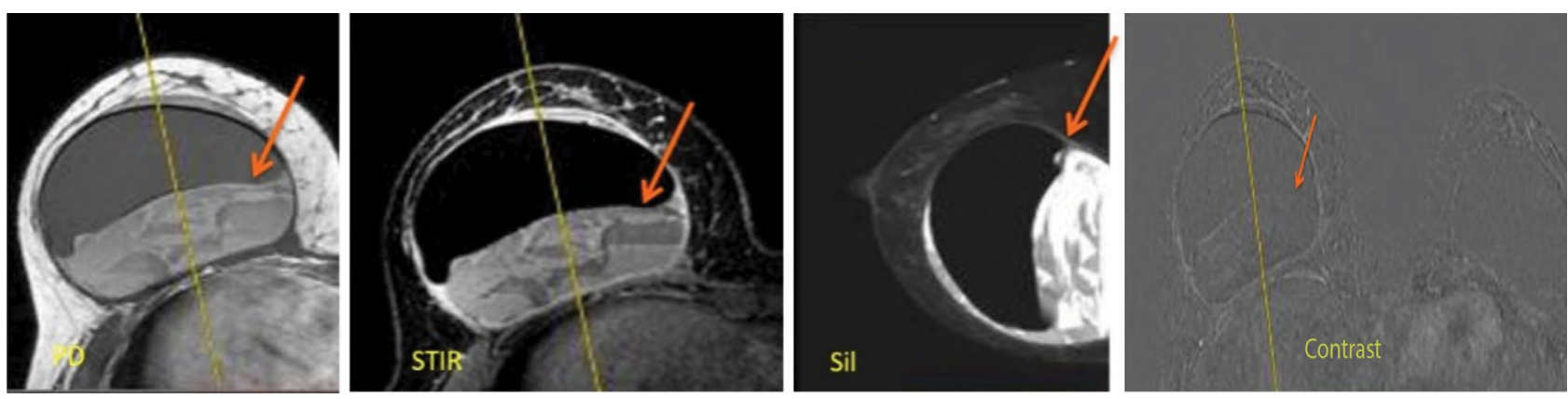

Figure 8 A 48-year-old patient with pain and enlargement on the right breast.

Notes: The MRI shows an intracapsular fluid fill around the implant with heterogeneous, signal compatible with hematoma. There is no mass enhancement after the contrast media injection. Arrows indicate limit between prosthesis and hematoma.

Abbreviations: PD, proton density; STIR, Short TI inversion recovery; Sil, silicone; MRI, magnetic resonance imaging.

A

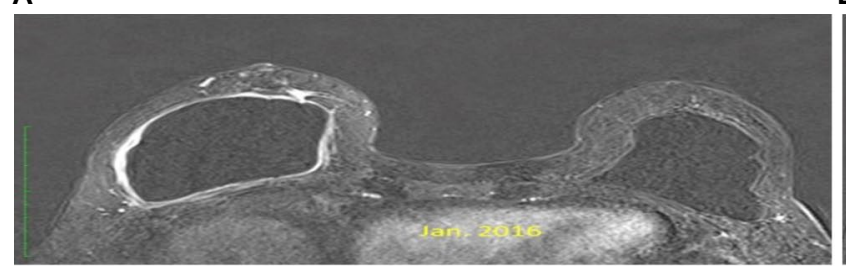

B

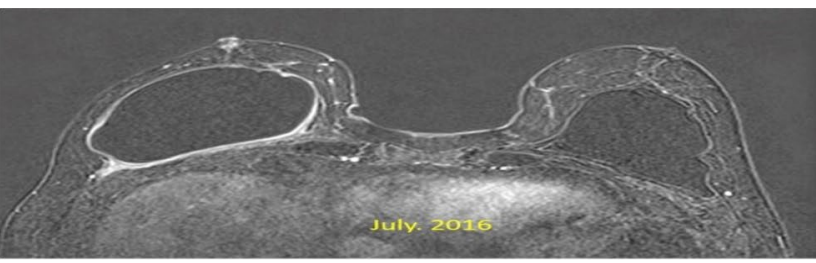

Figure 9 A 35-year-old patient with signs of fluid collection in the right breast 7 years after implantation.

Notes: The image was acquired in January 2016 and shows (A) the diffuse thickening of the fibrous capsule, with contrast enhancement in the adjacent fibrous glandular tissue. The patient was subjected to percutaneous biopsy and was diagnosed with mastitis. Antibiotic treatment was performed and resulted in clinical improvement. An MRI image shows (B) the control of the disease at 6 months and improvement of the image status. Abbreviation: MRI, magnetic resonance imaging.

prosthesis replacement is performed because of the complications reported for ALCL.

\section{Acknowledgments}

The authors are grateful to:

- Marcelo L Balancin, MD, from Diagnostika - Patologia Cirúrgica e Citologia, who provided us the histopathologic images of the SIGBIC;
- Raquel Civolani Marques Fernandes, MD, PhD, from FEMME - Laboratório da Mulher, who provided us the histopathologic images of the ALCL.

\section{Author contributions}

All authors contributed toward data analysis, drafting and critically revising the paper and agree to be accountable for all aspects of the work. 


\section{Disclosure}

The authors report no conflicts of interest in this work.

\section{References}

1. inca.gov.br [homepage on the internet]. Rio de Jajeiro: INCA- Ministério da Saúde; c1996-2016. Available from: http:/www2.inca.gov.br/wps/wcm/ connect/tiposdecancer/site/home/mama. Accessed October 27, 2016.

2. Joks M, Mysliwiec K, Lewadoski K. Primary breast lymphoma-a review of the literature and report of three cases. Arch Med Sci. 2011;7(1):27-33.

3. Miranda RN, Lin L, Talwalkar SS, et al. Anaplastic large cell lymphoma involving the breast: a clinicopathologic study of 6 cases and review of the literature. Arch Pathol Lab Med. 2009;133:1383-1390.

4. Jeanneret-Sozzi W, Taghian A, Epelbaum R, et al. Primary breast lymphoma: Patient profile, outcome and prognostic factors. BMC Cancer. 2008;8:86-93

5. Binmahfouz A, Steinke K. A case report of breast implantassociated anaplastic large cell lymphoma: The good, the bad, and the ugly. Int $J$ Case Rep Images. 2016;7(8):537-541.

6. Wiseman C, Liao KT. Primary lymphoma of the breast. Cancer. 1972; 29:1705-1712.

7. Jarjis RD, Hansen LB, Matzen SH. The non-specific symptoms of breast implant-associated anaplastic large cell lymphoma resulting in delayed diagnosis: a case-based review. JPRAS Open. 2015;6:1-4.

8. Scheliga AA, Reinert T, Santos AL, Stefanoff CG. Linfoma primário da mama: apresentação clínica e características histopatológicas e moleculares. Revista Brasileira de Oncologia Clínica. 2012;8:79-87. Portuguese.

9. Xu J, Wei S. Breast implant - associated anaplastic large cell lymphoma. Arch Pathol Lab Med. 2014;138(6):842-846.

10. Sahoo S, Rosen PP, Feddersen RM, et al. Anaplastic large cell lymphoma arising in a silicone breast implant capsule: a case report and review of the literature. Arch Pathol Lab Med. 2003;127(3):e115-e118

11. Roden AC, Macon WR, Keeney GL, et al. Seroma-associated primary anaplastic large-cell lymphoma adjacent to breast implants: an indolent T-cell lymphoproliferative disorder. Mod Pathol. 2008;21(4):455-463.

12. Olack B, Gupta R, Brooks GS. Anaplastic large cell lymphoma arising in a saline breast implant capsule after tissue expander breast reconstruction. Ann Plast Surg. 2007; 59(1):56-57.
13. Keech JA, Creech BJ. Anaplastic T-cell lymphoma in proximity to a saline-filled breast implant. Plast Reconstr Surg. 1997;100: 554-555.

14. Kim B, Predmore ZS, Mattke S, van Busum K, Gidengil CA. Breast implant-associated anaplastic large cell lymphoma: update results from a structured expert consulation process. Plast Reconstr Surg Glob Open. 2015;3(1):e296.

15. Clemens MW, Miranda RN. Coming of age: Breast implantassociated anapestic large cell lymphoma after 18 years of investigation. Clin Plast Surg. 2015;42:605-613.

16. fda.gov [homepage on the internet]. Silver Spring: U.S. Food and Drug Administration; [Updated January 26, 2011]. Available from: http:/www.fda.gov/NewsEvents/Newsroom/PressAnnouncements/ ucm 241090.htm. Accessed October 27, 2016.

17. Cohen Tervaert JW, Kappel RM. Silicone implant incompatibility syndrome (SIIS): a frequent cause of ASIA (Shoenfeld's syndrome). Immunol Res. 2013;56(2-3):293-298.

18. Thompson PA, Lade S, Webster H, Ryan G, Prince HM. Effusion-associated anaplastic large cell lymphoma of the breast: time for it to be defined as a distinct clinicopathological entity. Haematologica. 2010:95(11): 1977-1979.

19. Spear SL, Rottman SJ, Glicksman C, Bown M, Al-Attar A. Late seromas after breast implants: theory and practice. Plast Reconstr Surg. 2012; 130(2):423-435.

20. fda.gov [homepage on the internet]. Silver Spring: U.S. Food and Drug Administration; [Updated August 13, 2013]. Available from: http://www.fda.gov/MedicalDevices/ProductsandMedicalProcedures/ ImplantsandProsthetics/BreastImplants/ucm064348.htm. Accessed October 27, 2016

21. Peters W, Fornasier V, Howarth D. Late unilateral hematoma after breast augmentation. Plast Surg (Oakv). 2014;22(1):18-21.

22. Rubino C, Brongo S, Pagliara D, et al. Infections in breast implants: a review with a focus on developing countries. JInfect Dev Ctries. 2014;8(9): 1089-1095.

23. Kim B, Roth C, Young VL, et al. Anaplastic large cell lymphoma and breast implants: results from a structured expert consultation process. Plast Reconstr Surg. 2011;128(3):629-639.

24. Talwalkar SS, Miranda RN, Valbuena JR, et al. Lymphomas involving the breast: a study of 106 cases comparing localized and disseminated neoplasms. Am J Surg Pathol. 2008;32:1299-1309.
Breast Cancer - Targets and Therapy

\section{Publish your work in this journal}

Breast Cancer - Targets and Therapy is an international, peerreviewed open access journal focusing on breast cancer research, identification of therapeutic targets and the optimal use of preventative and integrated treatment interventions to achieve improved outcomes, enhanced survival and quality of life for the cancer patient.

\section{Dovepress}

The manuscript management system is completely online and includes a very quick and fair peer-review system, which is all easy to use. Visit http://www.dovepress.com/testimonials.php to read real quotes from published authors. 